Antlge de Realdie

\title{
BRONQUIOLITE AGUDA, UMA REVISÃO ATUALIZADA
}

Werther Brunow de Carvalho, Cíntia Johnston*, Marcelo Cunio Fonseca

Trabalho realizado na Universidade Federal de São Paulo / Escola Paulista de Medicina

*Correspondência:

Rua da Consolação, 3367, conj. 104

Edifício Flávia - São Paulo/SP

Cep: 01416-001

Tel: (11) 8232-0542

cintiajohnston@terra.com.br

\section{RESUMO}

A bronquiolite aguda (BA) é um diagnóstico freqüente de internação hospitalar em pediatria, ocasionada principalmente pelo vírus sincicial respiratório (VSR). Ocorre epidemicamente nos meses de outono e inverno. Algumas populações de crianças (recém-nascidos pré-termo, cardiopatia congênita, doença pulmonar crônica, imunocomprometidos, desnutridos, entre outros) apresentam maior risco de morbidade e mortalidade. Os vírus multiplicam-se nas células epiteliais cilliadas, e a inflamação e os debris celulares ocasionam obstrução da via aérea, hiperinsuflação, atelectasia localizada, chiado e alterações das trocas gasosas. Não existem evidências definitivas em relação aos tratamentos utilizados para esta doença. $O$ tratamento inclui a utilização de oxigênio, hidratação, beta-2 agonistas por via inalatória, epinefrina racêmica, DNase recombinante, fisioterapia respiratória, entre outros. Medidas profiláticas: administração de anticorpos monoclonais (palivizumab).

A maioria das crianças com BA, independentemente da gravidade da doença, recuperam-se sem seqüelas. $O$ curso natural desta doença, habitualmente, varia entre sete a dez dias, mas algumas crianças permanecem doentes por semanas.

UnIteRmos: Bronquiolite. Vírus sincicial respiratório. Infecção do sistema respiratório. Pediatria. Terapia intensiva.

\section{INTRODUÇÃO}

A BA é a síndrome do sistema ventilatório (SV) mais freqüente e grave que acomete a criança jovem nos dois primeiros anos de vida (sendo encontrada em crianças até 2-3 anos de idade) e o pico de incidência ocorre abaixo dos 12 meses de idade. Tem um padrão epidêmico com prevalência no outono e inverno. Durante o período de inverno, é a causa mais freqüente de hospitalização de lactentes'. Inicia-se com os sintomas das infecções virais do SV superior (febre e coriza), que progridem em quatro a seis dias, evoluindo para o acometimento do SV inferior (tosse e chiado).

Em geral, é uma doença autolimitada, com uma taxa de mortalidade baixa $(<1 \%)$, embora possa ser mais elevada (30\%) em grupos de crianças de alto risco (prematuros, com displasia broncopulmonar, cardiopatia congênita e imunocomprometidos, desnutridos, entre outros), em que está associada a doença prolongada e maior risco de óbito.

Crianças com idade inferior a seis meses apresentam risco de doença grave decorrente da BA. A doença é sazonal e coincide com as epidemias de infecções secundárias a patógenos respiratórios

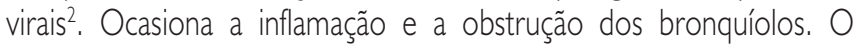
agente etiológico mais freqüente é o VSR, mas a BA também pode ser ocasionada pelo parainfluenza, adenovírus, influenza, Mycoplasma pneumoniae, rinovírus, Chlamydia pneumoniae, metapneumovírus humano e coronavírus.

\begin{tabular}{ll}
\hline \multicolumn{1}{c}{ Tabela I - Fatores de risco para a piora clínica de crianças com BA } \\
\hline Apresentação inicial & - taquipnéia (FR $>60-80$ irpm ou retrações) \\
& - hipóxia ( $\left.\mathrm{SaO}_{2}<90 \%\right)$ \\
& - dificuldade de se alimentar ou desidratação \\
Idade & - idade $<12$ meses (quanto menor a idade maior o risco) \\
Comorbidades & - displasia broncopulmonar \\
& - cardiopatia congênita \\
& - fibrose cística \\
& - imunodeficiência \\
Prematuridade & - idade gestacional <36 semanas \\
Outros & - desnutrição- baixo poder aquisitivo \\
& - aglomeração \\
& - pais e/ou familiares fumantes \\
& - predisposição genética para infecções por VSR \\
\hline
\end{tabular}

\section{Patógenos}

VSR

O VSR pode ser dividido em dois grandes grupos: A (cepa dominante) e B. Este vírus cresce de maneira ótima no pH de 7,5 e, embora seja sensível à temperatura, é recuperado após mais de uma hora em luvas contaminadas com secreção nasal infectada pelo vírus. Esta estabilidade no ambiente hospitalar contribui para colocálo como um patógeno nosocomial. 
A transmissão ocorre após contato ocular ou nasal com secreção contaminada. Os anticorpos séricos parecem oferecer alguma proteção contra esta infecção. Altos níveis de anticorpos maternos estão associados com menores taxas de infecção em lactentes. A administração profilática de anticorpos tem sido efetiva para reduzir, mas não para eliminar a doença grave pelo VSR. A infecção é mais grave e a replicação do VSR é mais prolongada em humanos e animais com deficiência de células- $T^{3}$.

\section{Vírus influenza}

O diagnóstico clínico deste vírus tem baixa sensibilidade, particularmente nas crianças com idade inferior a três anos ${ }^{4,5}$. Nos anos de 2003 e 2004, predominou a epidemia de uma cepa variante (A) Fujian/4 | |/2002), aumentando as complicações destas infecções, assim como a taxa de mortalidade 6 . A interrupção da vacinação contra o vírus associa-se ao aumento da mortalidade de crianças com idade entre um e quatro anos ${ }^{7}$.

Embora a infecção seja autolimitada, pode ocasionar complicações: pneumonia, síndrome de Reye, miosite, convulsão febril e encefalopatia aguda. A hospitalização, a doença grave e as complicações da doença ocorrem freqüentemente em crianças com idade inferior a dois anos e naquelas com fatores de risco (asma ou outra doença pulmonar crônica, doença cardíaca grave, imunocomprometidos, hemoglobinopatias e diabetes mellitus) ${ }^{8}$.

\section{Parainfluenza}

O padrão sazonal dos vírus parainfluenza tipos I, 2 e 3 são curiosamente interativos. O vírus parainfluenza tipo | causa epidemia definida e com maior número de casos de crupe do que BA, a cada dois anos. As epidemias do vírus parainfluenza tipos 2 são mais erráticas e ocorrem logo após a epidemia do tipo I, e as epidemias do vírus parainfluenza tipo 3 ocorrem anualmente (principalmente na primavera e no verão) e têm um tempo de ocorrência mais prolongado do que os tipos 1 e $2^{9}$.

O espectro da doença é similar ao do VSR, mas com menor taxa de hospitalização ${ }^{10}$. Na maioria das vezes, ocasiona infecção do SV superior; $30 \%$ a $50 \%$ dos casos são complicados por otite média. A pneumonia e a BA pelo vírus parainfluenza tipo 3 ocorrem principalmente nos primeiros seis meses de vida, mas com baixa incidência quando comparado ao VSR.

\section{Adenovírus}

Isolado freqüentemente na adenóide e em outros tecidos linfáticos. Atualmente, são identificados 51 sorotipos. Causa mais freqüente de infecção respiratória aguda e conjuntivite, pode ficar latente e ocasionar recrudecência posterior. Este é um DNAvírus e não possui envelope lipídico; é altamente estável fora das células do hospedeiro e pode se manter infectante à temperatura ambiente por duas semanas. Pode ser destruído pelo calor $\left(54^{\circ} \mathrm{C}\right.$ durante 30 minutos), desinfetantes e detergentes habituais e por agentes de higiene das mãos.

É transmissível entre pessoas pelas gotículas do SV e olhos e, no caso de adenovírus entérico, pelas fezes. $O$ período de incubação varia entre cinco e dez dias, não sendo comum a sua ocorrência

\begin{tabular}{ll}
\hline \multicolumn{1}{c}{ Tabela 2 - Síndromes clínicas causadas pelo adenovírus } \\
\hline$\frac{\text { Sistema }}{\text { Respiratório }}$ & Apresentação clínica \\
\hline & Sistema ventilatório superior: \\
& - faringite \\
& - coriza \\
& Sistema ventilatório inferior: \\
& - laringotraqueobronquite \\
& - tosse \\
& - BA \\
& - pneumonia \\
& - conjuntivite com doença respiratória \\
Ocular & - conjuntivite folicular aguda \\
& - ceratoconjuntivite epidêmica \\
& - febrefaringoconjuntival \\
Gastrintestinal & - diarréía \\
& - hepatite no hospedeiro \\
Urinário & -imunocomprometidos \\
Nervoso & - cistite hemorrágica \\
& - meningite asséptica \\
& - meningoencefalite, encefalite \\
Cutâneo & - mielite, paralisia flácida aguda \\
Infecção disseminada & - miosite \\
(Rns, imunocomprometidos) & - exantema \\
\hline & - falência dos múltiplos órgãos \\
\hline & \\
\hline
\end{tabular}

nos primeiros seis meses de vida, sugerindo uma proteção pelos anticorpos maternos. Com cinco anos de idade, $75 \%$ das crianças têm sorologia positiva para adenovírus. Os sorotipos $1-7$ são responsáveis pelas doenças respiratórias agudas (2\% a 3\% delas são ocasionadas pelo adenovírus, e ocorre acima de $8 \%$ nas crianças abaixo dos dois anos de idade)". As síndromes clínicas ocasionadas pelo adenovírus estão apresentadas na Tabela 2.

\section{Rinovírus}

A patogênese da doença não é completamente definida. As infecções decorrentes dele são a causa mais freqüente de crises de asma em crianças e em adultos'. Predomina no terceiro ano de vida com chiado recorrente ${ }^{13}$. Permanece indeterminado se fatores do hospedeiro, como a alteração da resposta imunológica inata, predispõem a doença mais grave e chiado, e se doenças respiratórias virais repetidas causam chiado devido à lesão de via aérea e pulmonar.

\section{Coronavírus}

A associação causal entre a doença respiratória febril e um novo coronavírus, distinto do coronavírus humano, foi demonstrada e denominada de síndrome respiratória aguda grave ${ }^{14}$. Os lactentes e crianças jovens não foram detectados como um grupo de risco, sendo a doença leve quando comparados com adultos. Sintomas freqüentes em crianças jovens: sinais de infecção do SV superior, sem a presença de sintomas como calafrios, rigidez e mialgia, presente em adultos $^{15}$. 
O período de encubação do vírus varia entre dois e sete dias (pode ser acima de dez dias), com febre $>38^{\circ} \mathrm{C}$, tosse seca, dispnéia com progressão para hipoxemia. Raios $X$ de tórax: infiltrado focal precoce, progredindo para uma generalização e infiltrado intersticial. As alterações radiológicas são indistinguíveis da broncopneumonia ocasionada por outros patógenos, podendo ocasionar BA. Alterações laboratoriais: leucopenia com linfopenia moderada e elevação das enzimas hepáticas.

\section{Metapneumovírus humano (MTH)}

O MTH foi descrito em 200 I na Holanda, com doença semelhante ao VSR, mas menos grave ${ }^{16}$. É o primeiro membro de um novo gênero de metapneumovírus (família Paramyxoviridae) que infecta humanos. $O$ estudo sorológico ${ }^{16}$ demonstrou que todas as crianças acima dos cinco anos de idade tinham anticorpos contra - MTH, sugerindo um alto nível de transmissão, e que provavelmente o vírus está circulando em humanos há 50 anos.

Este vírus tem distribuição universal e predomina nos meses de outono e inverno (climas temperados). Associado a vários quadros clínicos, incluindo: resfriado, BA, exacerbação de asma e doença obstrutiva da via aérea, pneumonia e ocasionalmente infecções graves em pacientes imunocomprometidos. Em crianças, infecções com associação do MTH e do VSR ocasionam BA grave ${ }^{17,18}$.

Sinais e sintomas decorrentes da infecção por MTH: febre (67\%), tosse (100\%), rinorréia (92\%), retrações torácicas (92\%), chiado (83\%), vômito (25\%) e diarréia $(8 \%)$. Diagnóstico clínico: BA (67\%), pneumonia (17\%), otite média aguda (50\%). Tempo médio de internação hospitalar: 4,5 dias. Com teste de reação em cadeia da polimerase, a proporção de crianças com infecção do SV varia entre 1,5\% e 10\% ${ }^{19}$.

O MTH acomete principalmente crianças abaixo de dois anos de idade (pico entre o terceiro e quinto meses de vida). A epidemia pode diferir das épocas sazonais de outros vírus. Devido à sua heterogenicidade, pode ocasionar múltiplas reinfecções durante a vida, especialmente em pessoas idosas e imunocomprometidas ${ }^{20,21}$.

\section{Patogênese}

A BA ocasionada pelo VSR é o resultado da infecção e da inflamação da mucosa respiratória. Os sintomas clínicos de obstrução do SV inferior são conseqüências da oclusão parcial das vias aéreas (VA) distais. O exame histológico revela: necrose do epitélio respiratório, inflamação monocitária com edema dos tecidos peribrônquios e obstrução das VA distais com plugs de muco e fibrina. Os lactentes são predispostos a BA devido ao pequeno calibre das VA distais e pela ausência de imunidade ativa contra o VSR e outros vírus respiratórios. A replicação viral induz a produção de mediadores inflamatórios pelas células epiteliais respiratórias (CER), contribuindo com a patogênese da doença. A descamação das CER, o edema da superfície mucosa e o aumento da reatividade da musculatura lisa da VA ocasionam os sintomas respiratórios da $\mathrm{BA}^{9}$.

Os mediadores inflamatórios produzidos pelas CER infectadas respondem de acordo com o patógeno viral envolvido. A gravidade clínica tem sido variável e a sua correlação com a cepa é inconclusiva.
A relação entre a gravidade da doença e a coinfecção com múltiplos vírus permanece não esclarecida?

\section{Diagnóstico diferencial}

Na ausência de sintomas prévios do SV superior, sugere-se que crianças com chiado de início agudo possam ter BA. Este diagnóstico deve ser considerado para crianças recém-nascidas com anormalidades (exemplo: doença cardíaca congênita). O refluxo gastresofágico (RGE), a pneumonia aspirativa ou a aspiração de corpo estranho podem mimetizar os sintomas de BA.

\section{Apresentação clíNICA}

A BA predomina nos períodos de inverno. Características iniciais da doença: rinorréía abundante e tosse "apertada" associada com aceitação inadequada de alimentos (quatro a seis dias após o início dos sintomas). A presença de febre varia de acordo com o patógeno, e lactentes com VSR estão freqüentemente febris no momento da consulta; naqueles com influenza ou parainfluenza a febre é maior do que $39^{\circ} \mathrm{C}$.

São freqüentes a taquipnéia, hipóxia leve a moderada e sinais de desconforto ventilatório (batimento de aletas nasais e retrações da musculatura ventilatória acessória). Ao exame, podem estar presentes tanto o chiado, crepitantes ou roncos, expansão torácica diminuída (padrão ventilatório apical) e fase expiratória prolongada. Outros achados observados são conjuntivites, otite média e rinite. Muitos apresentam o abdômen distendido devido à hiperinsuflação dos pulmões. Lactentes freqüentemente apresentam uma leve elevação do número de leucócitos, embora o diferencial dos leucócitos seja normal. A hipóxia pode ser observada, e a retenção de $\mathrm{CO}_{2}$ pode ocorrer nos casos graves.

Os vírus podem ser detectados de amostras de lavado nasal pela detecção de anticorpos por fluorescência indireta, reação de cadeia da polimerase, radioimunoensaio ou cultura viral. Os resultados de testes de diagnóstico viral devem ser utilizados para limitar o uso inadequado de antibióticos.

Achados radiográficos: hiperinsuflação, infiltrados grosseiros que são tipicamente migratórios e atribuíveis a atelectasias pósobstrutivas e preenchimento peribrônquico. A BA não é uma doença dos espaços alveolares e, caso haja um infiltrado verdadeiro, deve-se suspeitar de uma pneumonia de origem bacteriana secundária.

\section{Tratamento}

O julgamento clínico permanece sendo o critério padrão ouro para a admissão hospitalar de crianças com BA, e não pode ser substituído por critério objetivo. A saturação arterial de oxigênio $\left(\mathrm{SaO}_{2}\right)$ é o preditor clínico mais consistente para avaliar a piora clínica (variando o ponto de corte entre $90 \%$ e 95\%), porém a maioria das crianças nesta variação de $\mathrm{SaO}_{2}$ apresenta boa evolução clínica ${ }^{22}$. A idade inferior a três meses, história clínica de doenças, $\mathrm{SaO}_{2}$, freqüência respiratória (FR) e o esforço cardioventilatório devem ser observados. A SaO maior ou igual a 93\% não é determinante de admissão hospitalar. 
A SaO $<92 \%$, a prematuridade, recém-nascidos com idade gestacional inferior a 34 semanas, FR >70 ciclos por minuto (cpm), atelectasia pulmonar, aparência doente ou de toxicidade, e idade inferior a três meses estão associados com a doença mais grave (definida como incapacidade da criança em manter-se ativa e alerta ou bem hidratada). $\mathrm{A} \mathrm{SaO}<92 \%$ é o preditor mais objetivo de gravidade. Geralmente, FR $>80$ cpm e hipóxia com $\mathrm{SaO}_{2}<85 \%$ são preditores de cuidados em Unidade de Terapia Intensiva Pediátrica $(\mathrm{UTIP})^{23}$

O tratamento da BA tem se modificado durante os anos, mas permanece um tópico polêmico. Não existe tratamento com efetividade demonstrada e, portanto, a estratégia terapêutica empregada não apresenta evidências definitivas para toda a população.

\section{Hidratação e oxigenação}

Tratamento fundamental: hidratação e oxigenação adequadas, oferecendo líquidos por via oral / enteral ou, na impossibilidade desta, por via intravenosa. $\mathrm{A} \mathrm{SaO}_{2}$ deve ser mantida maior do que $92 \%{ }^{24}$. Estas medidas, associadas à monitorização adequada, constituem o tratamento de suporte universalmente aceito.

\section{Beta-2 agonistas}

A utilização dos beta-2 agonistas $(0,15 \mathrm{mg} / \mathrm{kg})$ segue sem uma recomendação científica definida, mas no contexto clínico continua sendo uma prática quase universal. Entretanto, deve ser suspensa caso 60 minutos após a inalação da droga não ocorra melhora ou ocorra piora clínica. Na infecção por VSR, a redução do diâmetro da via aérea e o chiado são decorrentes de pelo menos quatro causas: aumento da produção de secreção, projeção (sloughing) do epitélio lesado da via aérea para o lúmen, edema de mucosa e intersticial, e broncoconstrição mediada por possíveis mecanismos humorais ou neurogênicos, sendo que a contribuição de cada um destes fatores é variável entre os pacientes, particularmente no que se refere à broncoconstrição? $0^{9}$ Os beta-2 agonistas agem apenas na broncoconstrição, sendo mais efetivos quanto maior for a contribuição desta.

A terapêutica com broncodilatadores é mais efetiva no estágio inicial da infecção, momento em que as pequenas vias aéreas não estão obstruídas com secreções e debris celulares ${ }^{25,26}$.

Os resultados com a utilização dos anticolinérgicos (brometo de ipratrópio) são limitados e em nenhuma situação são superiores aos beta-2 agonistas, isoladamente ou combinados. A teofilina é indicada para as crianças com clínica de apnéia, entretanto, não existem estudos avaliando este aspecto.

\section{Adrenalina racêmica}

A adrenalina é mais eficaz do que a utilização do salbutamol / fenoterol. Dose de adrenalina racêmica: a 2,25\% é de $0,1 \mathrm{mg} / \mathrm{kg}$. e L-adrenalina: a $0,1 \%$ é de $0,05 \mathrm{mg} / \mathrm{kg}$ a cada quatro horas. Tratamento indicado exclusivamente em meio hospitalar, com controle clínico e monitorização da frequêencia cardíaca e eletrocardiografia. Algumas vezes, pode ocorrer um efeito rebote, sendo necessária a observação da criança durante uma a duas horas.

A diferença de resposta da epinefrina versus o albulterol pode ser melhor compreendida quando considerada a patogênese da infecção pelo VSR. A adrenalina, devido à sua atividade agonista alfa adrenérgica, é mais efetiva para reduzir o edema de mucosa intersticial e pode ser mais eficaz para "abrir" as pequenas VA do que a terapêutica com broncodilatadores beta adrenérgicos ${ }^{27}$.

\section{Corticóide inalatório e sistêmico}

Esta é uma terapêutica controversa, não sendo indicada para o tratamento de BA leve ou moderada. Uma revisão sistemática ${ }^{28}$ não demonstrou nenhum benefício do uso dos corticosteróides no manejo da BA. Para as crianças graves, submetidas à VPM (ventilação pulmonar mecânica), pode haver benefícios com a utilização de corticóides, porém eles provavelmente não previnem o broncoespasmo recorrente após a doença ${ }^{29}$.

A fisiopatologia da infecção ocasionada pelo VSR sugere que a ação antiinflamatória dos corticosteróides pode ser uma terapêutica efetiva, entretanto, as pesquisas efetuadas até o momento não justificam a utilização desta terapêutica, pois não foi demonstrada alteração nos achados clínicos, na admissão hospitalar e no tempo de internação hospitalar.

\section{Aerosolized recombinant human DNase}

Estudos $^{30,31}$ avaliaram os efeitos da aerosolized recombinant human DNase no tratamento de crianças com infecção pelo VSR. Em um estudo ${ }^{30}$, o escore do raio $X$ de tórax melhorou de forma significativa após a administração da DNase. Entretanto, não houve melhora significativa da $F R$, do chiado e das retrações musculares.

muco dos pacientes com fibrose cística (FC), bronquiectasias e BA pelo VSR contém uma quantidade significante de DNA extracelular dos leucócitos degenerados e dos debris epiteliais ${ }^{30} .0$ DNA aumenta a viscosidade e a aderência das secreções pulmonares. Nas infecções complicadas por atelectasia, as secreções brônquicas e os plugs mucosos também apresentam alta concentração de DNA. A DNase utilizada ${ }^{32}$ (aplicada por nebulização ou pela cânula, duas vezes ao dia até a melhora clínica) para pacientes pediátricos sem FC e com atelectasia, demonstrou melhora clínica rápida, após duas horas, e melhora radiológica após 24h para maioria das crianças do estudo.

\section{Ribavirina}

É um antiviral que inibe a síntese das proteínas estruturais dos vírus, diminuindo a sua replicação e a resposta da imunoglobulina E. Esta droga em aerossol não é efetiva para pacientes com imunidade normal, e a sua utilização está restrita para aqueles imunocomprometidos e com doença grave pelo VSR, embora a terapêutica não seja sustentada por pesquisas clínicas randomizadas.

\section{Outras medidas de tratamento}

Mistura hélio e oxigênio (heliox)

O heliox diminui o trabalho ventilatório (work of breathing $W O B$ ) e o chiado (sibilo) expiratório de crianças com doenças obstrutivas. Alguns estudos 33,34 analisaram os efeitos do heliox na infecção pelo VSR, verificando que este pode ser útil como um auxiliar para evitar a falência ventilatória e a intubação intratraqueal, mas não apresenta benefícios para os pacientes em VPM invasiva, e a sua utilização deve ser reservada para pacientes em UTIP. 
Carvalho WB et al.

Fisioterapia respiratória

Pode ser indicada durante todo curso da doença (em nível ambulatorial, de emergências, em enfermarias e UTIP), justificada pelas características fisiopatológicas da doença (acúmulo de secreções nas VA, obstrução e colapso de unidades alveolares, hiperinsuflação pulmonar) e pelos efeitos objetivos da fisioterapia respiratória: desobstrução brônquica, desinsuflação pulmonar e recrutamento alveolar.

Tratamento de pacientes com BA em UTIP: terapia de posicionamento; aumento do fluxo expiratório (AFE) associado ou não à vibração manual; hiperinsuflação pulmonar manual (HPM) associada ou não à pressão expiratória no final da expiração (EPAP); hiperinsuflação pulmonar (HP) com o aparelho de VPM associada ou não à técnica de direcionamento de fluxo manual (DF); HPM associada ou não à técnica de DF, e aspiração das vias aéreas.

Entretanto, existem até o momento apenas três estudos clínicos, randomizados controlados ${ }^{35-37}$, analisando os efeitos da fisioterapia respiratória para crianças com BA. Na revisão sistemática ${ }^{38}$, constaram no tratamento recomendado: a terapia de posicionamento, o recrutamento alveolar, as técnicas de AFE, a vibração manual e a aspiração das vias aéreas.

A aspiração das VA é uma medida paliativa efetiva para a desobstrução traqueobrônquica das crianças com VSR. Aproximadamente $60 \%$ da resistência respiratória está localizada nas VA superiores e, nos lactentes, que respiram predominantemente pela via nasal, a depuração destas secreções pode ter um impacto positivo no WOB e aliviar os sintomas.

Oxigenação de membrana extracorpórea (ECMO)

A ECMO é uma boa opção de tratamento para as crianças com doença grave que não podem ser mantidas em VPM, pois com este tratamento pode-se manter a ventilação e a condição cardiocirculatória.

Óxido nítrico inalatório (NOI)

Melhora a oxigenação e a resistência do SV de crianças com infecção grave pelo VSR ${ }^{39}$. Entretanto, pela resposta variada entre os pacientes, acredita-se que o NOi não melhora a mecânica pulmonar $^{40}$. A sua utilização deve ser reservada para os pacientes com hipoxemia grave e refratária ao suporte ventilatório.

Surfactante exógeno

As crianças com BA por VSR apresentam deficiência de surfactante, tanto em quantidade quanto na habilidade para diminuir a tensão superficial dos alvéolos. O surfactante exógeno é uma terapêutica potencial para os pacientes com BA ${ }^{41,42}$. É importante para a patência das pequenas VA e da complacência pulmonar, mas o seu uso é restrito a pacientes em UTIP e neonatais.

\section{VPM convencional}

Está indicada para crianças com padrão obstrutivo e aquelas com doença restritiva com hipoxemia, utilizando-se uma modalidade de pressão controlada. Pode-se também optar por uma modalidade mista (com pressão regulada volume controlado - PRVC).
Em razão da possibilidade de PEEP intrínseca, deve-se procurar manter os parâmetros da VPM com uma FR baixa $(20 \mathrm{cpm})$ e relação I:E de I:3. Inicia-se com uma PEEP de $5 \mathrm{cmH}_{2} \mathrm{O}$, ajustando o seu valor segundo o grau de recrutamento alveolar e resposta clínica obtida.

Ventilação com oscilação alta freqüência (VOAF)

Está indicada para os pacientes em VPM convencional que apresentam piora clínica ou extravasamento de gás significativo (pneumotórax, enfisema intersticial, pneumopericárdio). Também é indicada no tratamento das doenças restritivas com índice de oxigenação maior do que 13.

A principal vantagem da utilização da VOAF é a possibilidade de se otimizar a ventilação e a oxigenação com menor risco de lesão pulmonar induzida pelo aparelho de VPM.

Ventilação não invasiva com pressão positiva (VNIPP)

Benefícios: mantém as VA abertas, melhora o fluxo expiratório, diminui a capacidade residual funcional, melhora a complacência pulmonar, facilita a mobilização de secreções, diminui o WOB, melhora a troca gasosa e preserva a síntese e a liberação de surfactante. A VNIPP está indicada como primeira escolha de suporte ventilatório nos episódios de apnéia, seja no modo de pressão contínua nas vias aéreas (CPAP) ou de pressão em dois níveis (BIPAP) ${ }^{43}$.

Quando se opta pelo uso da CPAP, recomenda-se iniciar com 4 $\mathrm{cmH}_{2} \mathrm{O}$ a $6 \mathrm{cmH}_{2} \mathrm{O}$; se a opção for pela BIPAP, recomenda-se iniciar com pressão positiva inspiratória (IPAP) de $8 \mathrm{cmH}_{2} \mathrm{O}$ e pressão positiva expiratória (EPAP) de $4 \mathrm{cmH}_{2} \mathrm{O}$. A modificação dos parâmetros deve ser efetuada de acordo com a resposta clínica da criança.

\section{Profilaxia}

Medidas para se prevenir a infecção pelo VSR: utilização de vacinas (imunização ativa) e de imunoglobulinas por via intravenosa. Os esforços para se obter uma vacina efetiva persistem sem a obtenção de resultados até o momento.

A imunização passiva pode ser realizada com anticorpos monoclonais (palivizumab) contra o VSR (dose intramuscular: I5 $\mathrm{mg} / \mathrm{kg} /$ dose, uma vez por mês durante os meses epidêmicos). A eficácia da imunização passiva é de 1/200; reduz as taxas de hospitalização em 55\% pelo VSR. Prematuros sem doença pulmonar crônica apresentam maior benefício com a terapêutica com o palivizumab. As orientações atualizadas para a utilização desta terapêutica foram publicadas pela Academia Americana de Pediatria em $2003^{44}$, devendo ser utilizada para crianças com doença cardíaca congênita e com alterações hemodinâmicas significativas.

\section{Prognóstico}

A maioria das crianças com BA, independente da gravidade da doença, recuperam-se sem seqüelas. $O$ curso natural desta doença varia entre sete a dez dias, mas algumas crianças permanecem doentes por semanas. 
Conflito de interesse: não há.

\section{SUMMARY}

\section{ACUTE BRONCHIOLITIS, AN UPDATED REVIEW}

Acute bronchiolitis $(A B)$ is a frequent cause of hospitalization among children and its main etiological agent is respiratory syncytial virus (RSV). It occurs epidemically during autumn and winter. Some populations of children such as premature newborns, infants with congenital heart disease and those with chronic lung disease, immunocompromised, undernourished, among others, present increased morbidity and mortality risk.

The virus multiplies in epithelial ciliated cells while inflammation and cellular debris cause obstruction of the airways, hyperinflation, atelectasis, and wheezing and gas exchange imbalance. Definitive evidence still does not exist about treatment of this disease, Treatment includes oxygen therapy, hydration, inhaled beta-2 agonists, racemic epinephrine, recombinant DNase and respirotherapy, among others. Prophylactic measures include administration of monoclonal antibodies.

The majority of children with $A B$, independent of disease severity, recover without sequels. The natural course of this disease usually varies, from seven to ten days, however some children may not recover for weeks. [Rev Assoc Med Bras 2007; 53(2): 182-8]

KEY WORDS: Bronchiolitis. Respiratory syncytial virus. Respiratory tract infection. Pediatrical critical care. Respirotherapy.

\section{REFERÊNCIAS}

I. Holman RC, Shay DK, Curns AT, Lingappa JR, Anderson LJ. Risk factors for bronchiolitis-associated deaths among infants in the United States. Pediatr Infect Dis J. 2003;22:483-90.

2. Leader $\mathrm{S}$, Kohlhase $\mathrm{K}$. Recent trends in severe respiratory syncytial virus (RSV) among US infants, 1997 to 2000. J Pediatr. 2003;|43:SI27S32.

3. McCarthy CA, Hall CB. Respiratory syncytial vírus:concerns and control. Pediatr Rev. 2003;24:301-9.

4. Centers for Diseases Control. Prevention and control of influenza. MMWR Morb Mortal Wkly Rep. 2005;54: I-40.

5. Peltola V, Reunanen T, Ziegler T, Silvennoinen H, Heikkinen T. Accuracy of clinical diagnosis of influenza in outpatient children. Clin Infect Dis. 2005; 4 I: I | 98-200

6. Bhat N, Wright JG, Broder KR, Murray EL, Greenberg ME, Glover MJ, et al. Influenza Special Investigations Team. Influenza-associated deaths among children in the United States, 2003-2004. N Engl J Med. 2005;353(24):2559-67.

7. Sugaya N, Takeuchi Y. Mass vaccination of schoolchildren against influenza and its impact on the influenza-associated mortality rate among children in Japan. Clin Infect Dis. 2005;41:939-47.

8. Hillenbrand K. Antiviral therapy for influenza infections. Pediatr Rev. 2005;26:427-8.

9. Hall CB. Respiratory syncytial vírus and parainfluenza vírus. N Engl J Med. 2001;344:1917-28.

10. Reed G, Jewett PH, Thompson J, Tollefson S, Wright PF. Epidemiology and clinical impact of parainfluenza virus infections in otherwise healthy infants and young children < 5 years old. J Infect Dis. 1997; 175:80713.

I I. Langley JM. Adenoviruses. Pediatr Rev. 2005;26:244-9.

12. Kling S, Donninger H, Williams Z, Vermeulen J, Weinberg E, Latiff K, et al. Persistence of rhinovirus RNA after asthma exacerbation in children. Clin Exp Allergy. 2005;35:672-8.

1 3. Lemanske RF Jr, Jackson DJ, Gangnon RE, Evans MD, Li Z, Shult PA, et al. Rhinovirus illnesses during infancy predict subsequent childhood wheezing. J Allergy Clin Immunol. 2005; I 6:57|-7.

I 4. Ksiazek TG, Erdman D, Goldsmith CS, Zaki SR, Peret T, Emery S, et al. SARS Working Group. A novel coronavirus associated with severe acute respiratory syndrome. N Engl J Med. 2003;348:1953-66.

1 5. Hon KL, Leung CW, Cheng WT, Chan PK, Chu WC, Kwan YW, et al. Clinical presentations and outcome of severe acute respiratory syndrome in children. Lancet. 2003;36 I(9370): I70I-3.

I6. Van den Hoogen BG, Jong JC, Groen J, Kuiken T, Groot R, Fouchier $\mathrm{RA}$, et al. A newly discovered human pneumovirus isolated from young children with respiratory tract disease. Nat Med. 2001;7:719-24.

17. Semple MG, Cowell A, Dove W, Greensill J, McNamara PS, Halfhide $C$, et al. Dual infection of infants by human metapneumovirus and human respiratory syncytial virus is strongly associated with severe bronchiolitis. J Infect Dis. 2005; 191:382-6.

18. Van den Hoogen BG, Bestebroer TM, Osterhaus AD, Fouchier RA. Analysis of the genomic sequence of a human metapneumovirus. Virology. 2002;295: I 19-32.

19. Nissen MD, Siebert DJ, Mackay IM, Sloots TP, Withers SJ. Evidence of human metapneumovirus in Australian children. Med J Aust. 2002; 1 76: 188.

20. Boivin G, De Serres G, Cote S, Gilca R, Abed Y, Rochette L, et al. Human metapneumovirus infections in hospitalized children. Emerg Infect Dis. 2003, 9:634-40.

21. Garcia-Garcia ML, Calvo C, Martin F, Perez-Brena P, Acosta B, Casas I. Human metapneumovirus infections in hospitalised infants in Spain. Arch Dis Child. 2006;91:290-5.

22. Lind I, Gill JH, Calabretta NC. What are hospital admission criteria for infants with bronchiolitis? Clin Inquiries. 2006;55:67-9.

23. Brooks AM, McBride JT, McConnochie KM, Aviram M, Long C, Hall CB. Predicting deterioration in previously healthy infants hospitalized with respiratory syncytial virus infection. Pediatrics. 1999;104(3 Pt I):463-7.

24. Black CP. Systematic review of the biology and medical management of respiratory syncytial virus infection. Respir Care. 2003;48:209-31.

25. Torres A Jr, Anders M, Anderson P, Heulitt MJ. Efficacy of metered-dose inhaler administration of albuterol in intubated infants. Chest. | 997; | | 2:484-90.

26. Derish M, Hodge G, Dunn C, Ariagno R. Aerosolized albuterol improves airway reactivity in infants with acute respiratory failure from respiratory syncytial virus. Pediatr Pulmonol. 1998;26:12-20.

27. Barr FE, Patel NR, Newth CJ. The pharmacologic mechanism by which inhaled epinephrine reduces airway obstruction in respiratory syncytial virus-associated bronchiolitis. J Pediatr. 2000;136:699-700.

28. Patel H, Platt R, Lozano JM, Wang EE. Glucocorticoids for acute viral bronchiolitis in infants and young children. Cochrane Database Syst Rev. 2004;(3): CD004878.

29. Van Woensel JB, Wolfs TF, Van Aalderen WM, Brand PL, Kimpen JL. Randomised double blind placebo controlled trial of prednisolone in children admitted to hospital with respiratory syncytial virus bronchiolitis. Thorax. 1997;52:634-7.

30. Nasr SZ, Strouse PJ, Soskolne E, Maxvold NJ, Garver KA, Rubin BK, et al. Efficacy of recombinant human deoxyribonuclease I in the hospital management of respiratory syncytial virus bronchiolitis. Chest. 200I; | 20:203-8.

31. Merkus PJ, Hoog M, Van Gent R. DNase treatment for atelectasis in infants with severe respiratory syncytial virus bronchiolitis. Eur Respir J. $2001 ; 18: 734-7$.

32. Hendriks T, Hoog M, Lequin MH, Devos AS, Merkus PJ. DNase and atelectasis in non-cystic fibrosis pediatric patients. Crit Care. 2005; 9:R35I-6.

33. Martinon-Torres F, Rodriguez-Nunez A, Martinon-Sanchez JM. Heliox therapy in infants with acute bronchiolitis. Pediatrics. 2002; 109:68-73. 
34. Cambonie G, Milesi C, Fournier-Favre S, Counil F, Jaber S, Picaud JC, et al. Clinical effects of heliox administration for acute bronchiolitis in young infants. Chest. 2006;129:676-82.

35. Webb MSC, Martin JA, Cartlidge PHT. Chest physiotherapy in acute bronchiolitis. Arch Dis Child. 1985;60:1078-9.

36. Nicholas KJ, Dhouieb MO, Marshal TG. An evaluation of chest physiotherapy in the management of acute bronchiolitis. Changing clinical practice. Physiotherapy. 1999,85:669-74.

37. Bohe L, Ferrero ME, Cuestas E, Polliotto L, Genoff M. Indications of conventional chest physiotherapy in acute bronchiolitis. Medicina. (Buenos Aires) 2004:64:198-200

38. Perrotta C, Ortiz Z, Roque M. Chest physiotherapy for acute bronchiolitis in paediatric patients between 0 and 24 months old. Cochrane Databases Syst Rev. 2006;1.

39. Hoehn T, Krause M, Krueger M, Hentschel R. Treatment of respiratory failure with inhaled nitric oxide and high-frequency ventilation in an infant with respiratory syncytial virus pneumonia and bronchopulmonary dysplasia. Respiration. 1998;65:477-80.

40. Patel NR, Hammer J, Nichani S, Numa A, Newth CJ. Effect of inhaled nitric oxide on respiratory mechanics in ventilated infants with RSV bronchiolitis. Intensive Care Med. 1999;25:81-7.
4I. Tibby SM, Hatherill M, Wright SM, Wilson P, Postle AD, Murdoch IA. Exogenous surfactant supplementation in infants with respiratory syncytial virus bronchiolitis. Am J Respir Crit Care Med. 2000; | 62: | 25|-6.

42. Davison C, Ventre KM, Luchetti M, Randolph AG. Efficacy of interventions for bronchiolitis in critically ill infants: a systematic review and meta-analysis. Pediatr Crit Care Med. 2004;5:482-9.

43. Barbosa AP, Johnston C, Carvalho WB. Ventilação não-invasiva em neonatológica e pediatria. São Paulo: Editora Atheneu; 2007.p. I-273.

44. American Academy of Pediatrics. Revised indications for the use of palivizumab and respiratory syncytial virus immune globulin intravenous for the prevention of the respiratory syncytial infections (2003). [cited 2006]. Avaliable from: http//aappolicy.aappublications.org/cgi/reprint/ pediatrics; | |2/6/| 447.pdf. 